\title{
A novel peanut allergoid is safe and effective in immunotherapy in a peanut allergy mouse model
}

\author{
J Smit ${ }^{1 *}$, R Pieters ${ }^{1}$, M van Roest ${ }^{1}$, L Kruijssen ${ }^{1}$, S Koppelman² ${ }^{2}$ D-J Opstelten², H Van der Kleij ${ }^{2}$ \\ From Food Allergy and Anaphylaxis Meeting (FAAM 2013) \\ Nice, France. 7-9 February 2013
}

\section{Background}

Peanut is one of the most common foods responsible for food-induced anaphylaxis in adults. Unfortunately, commonly used allergen-specific immunotherapy has not been successful for the treatment of food allergy because of the high risk of serious side-effects. Therefore, chemically modified allergen extracts with improved safety characteristics are being investigated for its potential use in immunotherapy.

\section{Methods}

Peanut extract (PE) from de-fatted peanut powder was modified by reduction of disulfide bonds and subsequent alkylation of the free Cys residues resulting in an allergoid $\mathrm{PE}(\mathrm{mPE})$. The potency of PE and $\mathrm{mPE}$ to induce PE-specific IgG was evaluated after i.p. injections in mice. Subsequently, mice were sensitized intra-gastrically for PE and either 1) subcutaneously challenged with different concentrations of PE or mPE to assess the safety profile of these product candidates, or 2) de-sensitized with subcutaneous injections of either PE or mPE (immunotherapy) for 4-6 weeks, followed by oral and i.p. challenges to assess the efficacy profile of the preparations. To assess the safety and efficacy profile of mPE compared to PE, body temperature was measured after challenge as an objective parameter of an anaphylactic shock response. In addition, during the course immunotherapy, blood samples were taken for analysis of antibody responses and mast cell activation.

\section{Results}

$\mathrm{PE}$ and $\mathrm{mPE}$ were equally potent in inducing PE-specific IgG antibodies in mice. Mice sensitized for PE experienced severe anaphylactic symptoms upon subcutaneous challenge with PE. Modified PE did not give rise to such reactions, even when given up to 100 fold higher dosages. Immunotherapy with both $\mathrm{PE}$ and $\mathrm{mPE}$ resulted in a significant reduction of the anaphylactic shock response upon systemic challenge. In addition, both $\mathrm{PE}$ and $\mathrm{mPE}$ were able to induce strong increases in the levels of PE-specific IgG1 and IgG2a compared to non-desensitized mice. Surprisingly, the mucosal mast cell response after challenge was decreased after immunotherapy with PE but not with $\mathrm{mPE}$.

\section{Conclusion}

Using in vivo mouse models, we have shown that an allergoid preparation of peanut extract has a significantly improved safety profile compared to its native counterpart while retaining its immunogenicity and efficacy profile. Furthermore, this study supports the usefulness of mouse models in testing safety, immunogenicity and efficacy of new immunotherapeutic preparations.

\section{Disclosure of interest}

None declared.

\section{Author details}

${ }^{1}$ Immunotoxicology, Institute for Risk Assessment Sciences, Utrecht, the Netherlands. ${ }^{2} \mathrm{HAL}$ Allergy BV, Leiden, the Netherlands.

Published: 25 July 2013

doi:10.1186/2045-7022-3-S3-P

Cite this article as: Smit et al.: A novel peanut allergoid is safe and effective in immunotherapy in a peanut allergy mouse model. Clinical and Translational Allergy 2013 3(Suppl 3):P1.

${ }^{1}$ Immunotoxicology, Institute for Risk Assessment Sciences, Utrecht, the

Netherlands

Full list of author information is available at the end of the article

(c) 2013 Smit et al; licensee BioMed Central Ltd. This is an Open Access article distributed under the terms of the Creative Commons Attribution License (http://creativecommons.org/licenses/by/2.0), which permits unrestricted use, distribution, and reproduction in any medium, provided the original work is properly cited. 